\title{
As Aventuras de Calculino: jogo para ensino de raciocínio lógico
}

\author{
Jessica A. Mioto, Esteic Janaina Santos Batista ${ }^{1}$, Quésia de Araújo Santos ${ }^{1}$, Cintia \\ A. Canteiro Bogarim, Anderson Corrêa de Lima
}

\author{
${ }^{1}$ Universidade Federal de Mato Grosso do Sul campus Ponta Porã (UFMS/CPPP) - \\ Ponta Porã - MS - Brasil \\ ${ }^{1}$ Bolsistas do Programa de Educação Tutorial - PET/SESu/MEC \\ \{jessica.mioto7, esteicejanaina, quesiaweb, cintiaadrianab, \\ anderson.correa.lima\} @gmail.com
}

\begin{abstract}
This paper aims to present the educational game for teaching mathematical logical reasoning, entitled Calculino Adventures. The game contains three modules: multiplication tables, labyrinth and puzzles; where they are based on a plot about the Calculino robot, which asks the user's help to solve the challenges. The children regarding the usability and fun of the game evaluated the game.
\end{abstract}

Resumo. Este trabalho tem por objetivo apresentar o jogo educacional para ensino de raciocínio lógico matemático, intitulado Aventuras de Calculino. $O$ jogo contém três módulos: tabuada, labirinto e quebra-cabeças; onde são embasados a partir de um enredo sobre o robô Calculino, que pede a ajuda do usuário para resolver os desafios. O jogo foi avaliado pelas crianças quanto a usabilidade e o divertimento do jogo.

\section{Introdução}

Diversas tecnologias podem e têm sido utilizadas no ambiente escolar, dentre elas, se destaca a tecnologia mobile, conquistando espaço cada vez mais frequente, além de ampliar o conceito de aula, de espaço e de tempo, desafiando as instituições a saírem do ensino tradicional em que o professor é o centro, para uma aprendizagem mais participativa e integrada [Moran, Masetto e Behrens 2009]. Aproximar sua utilização no ambiente escolar pode contribuir para um novo direcionamento na aprendizagem dos alunos, minimizando as dificuldades presentes no ambiente escolar, bem como ressaltando a contribuição da utilização do telefone celular como plataforma para usabilidade de jogos móveis educativos [Braga 2013].

É necessário que os jogos de caráter educacional sejam realizados a partir de um embasamento que esteja atrelado a princípios teóricos metodológicos claros e, ao mesmo tempo, forneça ao aluno um ambiente agradável, motivador e enriquecedor para que assim, por meio da experimentação do uso dessa tecnologia, seja possível que o aprendiz desenvolva habilidades quanto ao tema que se está trabalhando, possibilitando uma aprendizagem efetiva [Tarouco et al. 2004].

Para Amory (2001), os jogos educativos requerem enredos atraentes, pois sua utilização é capaz de afetar a motivação, funções cognitivas e a curiosidade do aprendiz. Por meio da interação do usuário com o jogo, o mesmo deve ser submetido a exploração e experimentação de um ambiente que lhe desperte a atenção, curiosidade e 
encantamento. Victal et al. 2015 afirmam que os jogos para serem úteis à educação não precisam ser sofisticados, basta que eles sejam desenvolvidos a partir de uma boa ideia, que tenham o elenco de missões e desafios, tenham feedbacks ao longo do jogar.

Junto com essa emergente utilização das tecnologias, cresce também a discussão em torno de questões que busquem trabalhar a qualidade e adequação de interfaces para softwares educacionais. Existe uma grande demanda por pesquisas, estudos e projetos que visam colaborar com o desenvolvimento de interfaces educacionais entendendo as necessidades do público infantil com o objetivo de facilitar a interação da criança com a ferramenta, tornando-a de fácil manipulação e eficaz no desempenho de seu objetivo principal: fornecer ao aluno o direcionamento para a aquisição de um determinado conhecimento [Read e Bekker 2011].

Desta forma, este trabalho apresenta um software educacional móvel voltado para o público infantil, que tem por objetivo o estímulo de raciocínio lógico, nomeado "As aventuras de Calculino". A Seção 1 apresenta a metodologia utilizada no desenvolvimento da ferramenta. A seção 3 apresenta a ferramenta e a Seção 4 a avaliação realizada com os usuários finais, as crianças. Por fim a Seção 5 apresenta as considerações finais e trabalhos futuros.

\section{Metodologia}

Na primeira etapa deste trabalho foi necessário fazer uma revisão literária de trabalhos relacionados a área de Interação Criança Computador com o intuito de entender melhor seus conceitos para que assim os mesmos pudessem ser implantados no desenvolvimento do game.

Em seguida iniciou-se o processo de implementação, para tanto foi utilizada a linguagem de programação Java juntamente com o ambiente de desenvolvimento Eclipse. Também foi utilizado o motor de jogos 2D Jeasy Game. Um guia sobre a ferramenta e um conjunto de tutoriais pode ser encontrada no link: jeasygame.esy.es.

A ilustrações utilizadas no jogo foram desenvolvidas e/ou ajustadas a medida que se fizeram necessárias, para isso foi-se utilizado o software Corel Draw.

\section{Aplicação desenvolvida}

Visto a importância da utilização das tecnologias digitais no processo educacional bem como a relevância dos jogos para o desenvolvimento de uma aprendizagem mais dinâmica, lúdica e interessante para crianças, nesta sessão é apresentada a aplicação desenvolvida neste trabalho.

Trata-se de um jogo educacional para dispositivos móveis com sistema operacional Android voltado para o público infantil, que tem por objetivo o estímulo de raciocínio lógico (Figura 1). O jogo nomeado "As Aventuras de Calculino" conta com 3 módulos: jogo da tabuada, labirinto e um quebra-cabeça (Figura 2). A aplicação tem por objetivo buscar o equilíbrio entre educação e ludicidade, favorecendo o desenvolvimento do raciocínio lógico por meio de um jogo que motive a criança a aprender enquanto se diverte. 
VI Congresso Brasileiro de Informática na Educação (CBIE 2017)

Anais dos Workshops do VI Congresso Brasileiro de Informática na Educação (WCBIE 2017)

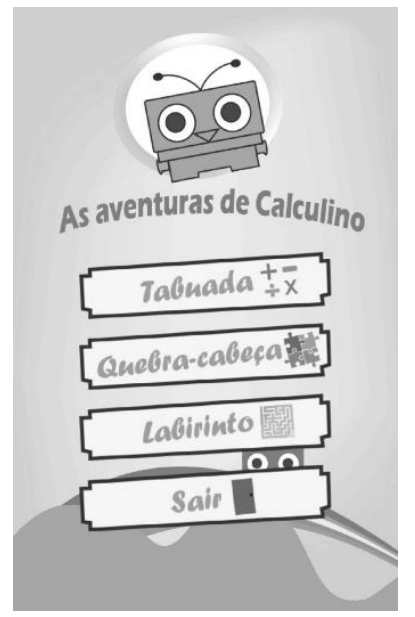

Figura 1. Tela inicial do jogo educacional

No módulo tabuada (Figura 2 (a)) o objetivo é trabalhar as operações matemáticas de adição e multiplicação. Neste módulo vários recursos como animações, sons e ambiente lúdico foram explorados com o intuito de tornar a atividade mais prazerosa e atraente aos olhos do usuário.

No jogo existe um trem em movimento que carrega em seus vagões determinadas operações, logo acima é disponibilizado um quadro com alguns números correspondentes aos resultados das operações presentes nos vagões (Figura 2). A tarefa do usuário é clicar no resultado de tal maneira que o mesmo caia dentro do vagão com a operação referente àquele resultado. A medida que o usuário vai acertando os resultados das operações a velocidade com a qual os vagões se movimentam aumenta, tornando assim o jogo mais desafiador para a criança.

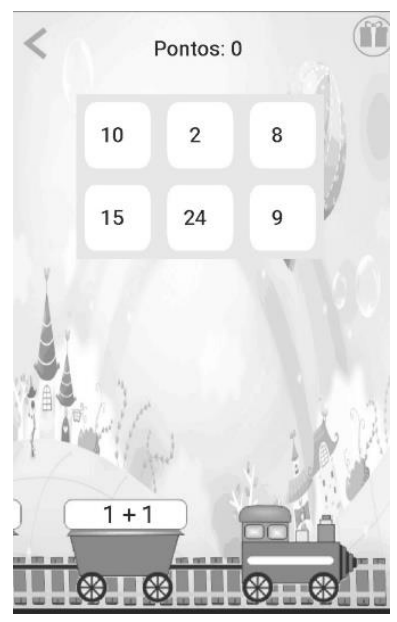

(a) Tabuada

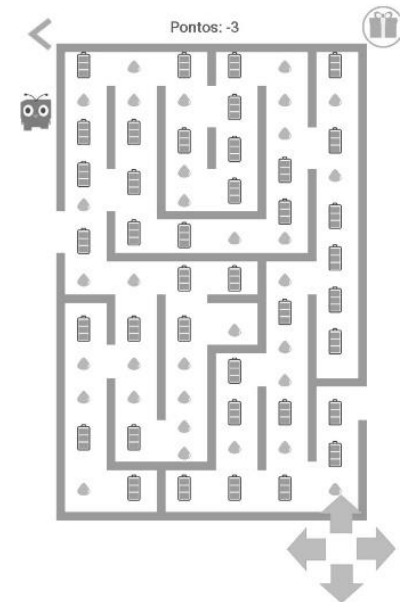

(b) Labirinto

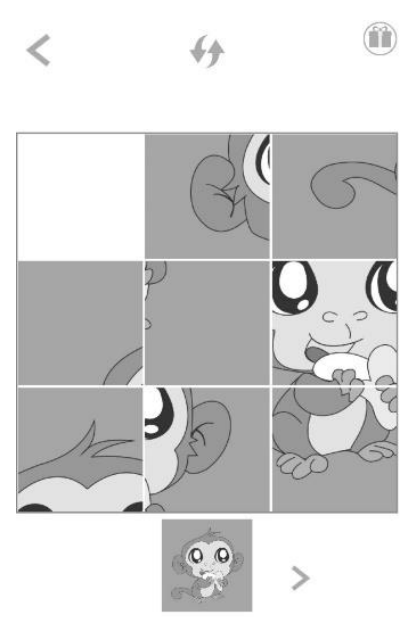

(c) Quebra-cabeças

\section{Figura 2. Módulos do jogo}

No jogo do labirinto o usuário deve movimentar o personagem na tela até encontrar uma saída que o levará a um outro labirinto (Figura 2 (b)). Nos caminhos do labirinto estão espalhados dois tipos de objeto: gotas de água e baterias. Toda vez que o usuário "captura" uma bateria ele soma um ponto em seu placar, e a cada vez que o mesmo "captura" uma gota de água, um ponto é descontado. 
Esse fator estimula ainda mais o desenvolvimento do raciocínio lógico tendo em vista que, além da finalidade dos labirintos tradicionais que é o de encontrar uma saída, o usuário precisa optar pela melhor forma de sair desse labirinto, ou seja aquela que maximize seu ganho de pontos. Na Figura 8 é apresentada a interface deste módulo.

O jogo conta ainda com o módulo do tipo quebra-cabeça. (Figura 2 (c)). Jogos desse gênero podem oferecer várias vantagens como estimular a concentração, $\mathrm{o}$ pensamento lógico, a comparação e a memória dentre outras. Neste módulo as imagens são divididas em 9 partes e o objetivo do usuário é movimentar essas partes até que a imagem esteja completamente formada.

\section{Avaliação do software}

O jogo foi avaliado por nove crianças de 8 a 12 anos, aplicando testes de usabilidade e divertimento. Para o teste de usabilidade foram utilizadas as heurísticas simplificadas e adaptadas para crianças, sendo delas: heurísticas de Nielsen para identificar problemas de usabilidade em uma interface de usuário; e as heurísticas de Malone que permitem avaliar o divertimento proporcionado por uma interface com o usuário. As heurísticas foram escolhidas por ter apresentado bons resultados, como no trabalho de [Valente 2011].

Os questionários com as heurísticas simplificadas foram impressos para a avaliação pelas crianças, mas foi disponibilizado online e podem ser acessados em: https://goo.gl/forms/uBbrmRzfJKhtvJ0F2 e https://goo.gl/forms/Q15TL2KosbhhO2iK2 para a revisão e leitura deste trabalho, pois não os apresentaremos aqui por questão de espaço.

$\mathrm{Na}$ avaliação utilizando as heurísticas, pode-se levantar algumas falhas no jogo como: não informar o quanto faltava para terminar o módulo que estavam jogando, repetindo algumas perguntas como no caso do módulo tabuada e também falta de elementos mais divertidos durante o jogo. Foram apontados falta de atalhos no jogo e affordances e ícones que utilizasse mais dos objetos do cotidiano. Nos outros quesitos o jogo foi bem avaliado, o que mostra que bastam pequenos ajustes para que ele seja mais divertido e atinja as metas de usabilidade.

\section{Considerações Finais}

O Calculino apresenta-se como uma ferramenta alternativa com foco educacional com o objetivo do ensino e aprendizagem de matemática e raciocínio lógico.

Pretende-se aprimorar a ferramenta com base nas avaliações realizadas pelas crianças, bem como, posteriormente aplicar outras avaliações com um número maior de crianças. Espera-se que a sua utilização possa ser fácil, amigável e prazerosa, proporcionando ao usuário usufruir de todas as funcionalidades que a tecnologia desenvolvida dispõe, além de colaborar para que o mesmo adquira uma aprendizagem significativa.

\section{Referências}

Amory, A. (2001). Building an educational adventure game: Theory, design, and lessons. Journal of Interactive Learning Research, 12(2), 249. Braga, D. B. (2016). Ambientes digitais: reflexões teóricas e práticas. Cortez Editora. 
VI Congresso Brasileiro de Informática na Educação (CBIE 2017)

Anais dos Workshops do VI Congresso Brasileiro de Informática na Educação (WCBIE 2017)

Moran, J. M. (2000). Novas tecnologias e mediação pedagógica. Papirus Editora.

Read, J.C. e Bekker, M.M. (2011) The Nature of Child Computer Interaction. In Proceedings of BCS-HCI 2011, Northumbria, UK.

Tarouco, L. M. R., Roland, L. C., Fabre, M. C. J. M., \& Konrath, M. L. P. (2004). Jogos educacionais. RENOTE: revista novas tecnologias na educação [recurso eletrônico]. Porto Alegre, RS.

Valente, J. F. P. (2011). Avaliação da Usabilidade e Diversão em Interfaces Web para Crianças caso de estudo escolinhas. pt. Mestrado Integrado em Engenharia Informática e Computação Tese de Mestrado Integrado em Engenharia Informática e Computação), Universidade do Porto, Faculdade de Engenharia.

Victal, .E. R. D. N, Junior H. A. P., Rios P. T. G. , Menezes C. S. d.(2015).Aprendendo sobre o uso de Jogos Digitais na Educação.Anais do XXI Workshop de Informática na Escola (WIE 2015).CBIE-LACLO 2015. Maceió, Alagoas. 